\title{
A Thematic Analysis of Speech Self-Awareness in the Community-Dwelling Elderly
}

\author{
Soomin Kim ${ }^{\mathrm{a}, \mathrm{b}}$, HyangHee Kim ${ }^{\mathrm{a}, c}$, Seok-In Nam ${ }^{\mathrm{d}}$, Han-Saem Kim ${ }^{\mathrm{e}}$ \\ ${ }^{a}$ Graduate Program in Speech and Language Pathology, Yonsei University, Seoul, Korea \\ ${ }^{b}$ Department of Neurology, Asan Medical Center, Seoul, Korea \\ 'Department and Research Institute of Rehabilitation Medicine, Yonsei University College of Medicine, Seoul, Korea \\ ${ }^{d}$ Graduate School of Social Welfare, Yonsei University, Seoul, Korea \\ 'Yonsei Institute of Language and Information Studies, Yonsei University, Seoul, Korea
}

Correspondence: HyangHee Kim, PhD, Graduate Program in Speech and Language Pathology, Yonsei University College of Medicine, 50-1 Yonsei-ro, Seodaemun-gu, Seoul 03722, Korea Tel: $+82-2-2228-3900$

Fax: +82-2-2227-7984

E-mail: h.kim@yonsei.ac.kr

Received: January 5, 2019

Revised: January 5, 2020

Accepted: January 16, 2020

This work was supported by the Ministry of Education of the Republic of Korea and the National Research Foundation of Korea (No. NRF2017S1A5A2A01025920).

This article is based on the master's thesis of the first author.

This article has been presented, in part, at 2018 ASHA Convention, Boston, USA.
Objectives: A self-report is often used to measure one's own problems and related quality of life. With typical ageing, speech may change and can restrict activity and participation. The purpose of this study is to explore themes in speech self-awareness reports stated by the community-dwelling older adults through a thematic analysis.

Methods: We interviewed 76 older persons (men:women $=23: 53$, mean age $=73.19 \pm 8.54$ ) from three senior community centers in Seoul. The participants described the changes in speech and the related activity limitations and participation restrictions by responding to the survey items; "Have you perceived any changes in your speech in the last year?" and "Does your speech cause any inconvenience in your daily life?". Thematic analysis using the NVivo 12 program was done based on the responses of the participants.

Results: Four main themes and 16 subthemes emerged from the analysis; and the main themes included 'characteristics of changes,' 'causes of changes,' 'activity limitations and participation restrictions due to changes,' and 'solutions to changes' in speech.

Conclusion: We observed that older persons experience changes in speech with diverse characteristics and that most of them consider these to be the result of ageing. They experience activity and participation problems and make an effort to resolve them. The main themes and subthemes could be served as key concepts upon providing intervention and/ or preventive education regarding geriatric speech problems.

Keywords: Ageing, Older adults, Self-awareness, Speech, Thematic analysis
'자가인식'이란 자신의 문제에 대하여 개인 스스로가 가지고 있 는 개념을 의미하고, '건강'은 자가인식을 통해 보고되는 대표적인 주제이며, 그 측정도구는 '건강에 대한 자가인식(Self-rated Health, SRH)'이라고 불린다(Flynn et al., 2013; Spiegel et al., 2014). 대상자 의 주관적인 보고임에도 불구하고, $\mathrm{SRH}$ 는 노인 대상자의 전반적 건강을 민감하게 평가한다고 알려져있다(Ocampo, 2010). 이에 피 로감, 의사소통기능 등 특정한 증세에 대한 대상자의 주관적인 인 식을 수집하기 위하여(Griffiths, Ullman, \& Harris, 2005) 각 영역 에서 자가보고 도구들을 개발하고 그 효율성과 정확성을 높이고 자 시도하고 있다(Bothe, \& Richardson, 2011; Dowdle, Glass, Anthony, \& Hettrich, 2017; Gruber-Baldini, Velozo, Romero, \& Shul- man, 2017; Katzan, Fan, Uchino, \& Griffith, 2016).

말장애 분야에서도 자가보고 도구들이 개발되어 활용되고 있는 데(Francis et al., 2017), 대표적인 예로 말장애지수(Speech Handicap Index) (Rinkel, Leeuw, van Reij, Aaronson, \& Leemans, 2008) 와 음성장애지수(Voice Handicap Index) (Jacobson et al., 1997)가 있다. 설문 평가로 실시되는 이러한 검사들은 세계보건기구(World Health Organization)가 제시한 국제 기능 장애 건강 분류(International Classification of Functioning, Disability and Health) 모델에 부합하여 장애로 인한 신체적, 기능적 변화에 대한 주관적 인식뿐 만 아니라 삶의 질에서의 변화에 대해서도 다룬다는 장점을 지닌다. 그러나 현재까지 출판된 자가보고 연구에는 몇 가지 한계점이 존 
재한다. 첫째로 기존의 도구들은 대부분 병리적 증상을 가진 환자 나 위험군만을 대상으로 하여(Francis et al., 2017), 정상 노인군의 변화는 민감하게 측정하지 못한다. 그러나 정상 노화의 과정에서 도 말은 변화하고(Hunter, Kapsner-Smith, Pead, Engar, \& Brown, 2012) 삶의 질에 영향을 미칠 수 있다(Yim, Kim, Kim, \& Yoo, 2013). 생리적, 인지적 혹은 정신적 건강 변화의 영향으로서(Yorkston, Bourgeois, \& Baylor, 2010) 노년층의 말 산출 능력은 청년층의 것과 는 차이를 갖는다. 구체적으로 호흡 측면에서 노년층은 발화길이가 짧고(Huber, 2008), 발성 측면에서는 거칠고 바람 새는 소리가 나고 불안정하며 음도가 단조롭다(Eichhorn, Kent, Austin, \& Vorperian, 2017). 특히 여성 노인은 음성의 기본 주파수가 감소하여 음도 에 변화가 생기고(Gorham-Rowan \& Laures-Gore, 2006; Goy, Fernandes, Pichora-Fuller, \& van Lieshout, 2013), 남성 노인은 진폭변 동률(shimmer) 지수가 높아져 음질이 나빠진다(Goy et al., 2013). 공명과 조음 측면에서 노년층은 비음이나 동시조음과 같이 복잡한 말소리 산출 과정에서 더 많은 오류를 보이며(D'Alessandro \& Fougeron, 2018), 운율 측면에서 노인의 말 속도는 연령이 증가함에 따라 느려진다(Bilodeau-Mercure \& Tremblay, 2016). 이러한 변화에도 불구하고 정상 노인을 대상으로는 연구가 거의 이루어지지 않았을 뿐만 아니라, 자가보고 평가도구 역시 개발된 바가 없다.

두 번째로, 기존의 도구는 주로 리커트 척도(Likert scale)를 사용 하여 자가인식을 분석한다(Jacobson et al., 1997; Rinkel et a., 2008). 이러한 양적 자료는 환자들이 느끼는 문제의 정도를 수치화한 후 표준화하며 나아가 절단점(cut-off score)을 제공한다는 장점이 있 다. 그러나 대상자가 자신의 인식을 직접적으로 설명하는 것이 아니 고 범주를 활용한 단계를 활용하여 중증도를 나타내기 때문에, 대 상자가 실제로 느끼는 문제의 실체를 면밀하게 파악하기는 어렵다.

이러한 한계점은 정상 노인이 가지고 있는 말 변화에 대한 자가 인식을 질적 측면에서 분석하여 보완할 수 있다. 앞서 밝혔듯이 노 인 스스로 자신의 말의 변화를 일상에서 인식하는지, 만일 그렇다 면 어떠한 문제를 느끼고 이로 인해 어떤 불편을 겪는지에 대하여 아직 보고된 바가 없다. 뿐만 아니라 이를 민감하게 평가할 수 있는 도구 또한 개발된 바 없다. 질적 연구는 경험자의 생생한 목소리를 바탕으로 현상을 이해한다는 점에서 대상자가 느끼는 변화와 그 영향을 개별적으로 면밀하게 밝힐 수 있으므로(Creswell, 2013; Damico \& Simmons-Mackie, 2003), 별도의 설문조사도구 없이도 노인의 말 변화에 대한 자가인식을 평가할 수 있다.

다양한 질적 연구의 접근법 중 '주제 분석(thematic analysis)'은 현상을 그대로 서술하는 데 목적을 둔 연구에서 주로 사용된다 (Braun \& Clarke, 2006; Guest, MacQueen, \& Namey, 2011). 다수
의 대상자에게서 수집한 발화에 내재한 '주제(theme)'가 무엇인지 를 발견하는 것이 연구의 핵심이다(Braun \& Clarke, 2006; Nowell, Norris, White, \& Moules, 2017). 여기서 주제는 전체 자료에서 반복 되어 나타나는 반응이라는 점에서 전체 발화에 대한 대표성을 지닌 다. 주제 분석의 장점은 유연한 연구 방법을 통하여 자료에 대해 풍 부하고 세세한 설명을 제공할 수 있다는 점이며, 특히 자료의 양이 많을 때 그 안에서 핵심이 되는 특징을 요약하는 데에 효과적이다.

앞서 밝혔듯이 본 연구에서는 정상 노인들을 대상으로 그들이 스스로 느끼는 '말' 변화를 정성적으로 살펴봄으로써 '말’이라는 중요한 의사소통능력이 사회적 참여와 활동에서 어떻게 기능적으 로 수행되고 있는지를 고찰해보고자 하였다. 이를 통하여 이들이 양질의 삶의 질을 유지하고 건강한 의사소통기능을 지속할 수 있 는 향후 연구 방향을 제시하고자 하였다.

\section{연구방법}

\section{연구대상}

본 연구의 대상자는 서울시내 총 세 곳의 노인복지관에서 모집된 정상 노인 총 76 명(남 23명, 여 53명)이다. 연구 대상 선정 기준은 다 음과 같다. (1) 55 세에서 100 세 사이의 지역사회 거주자로서, (2) 신 경학적 질환을 진단받지 않았으며, (3) 한국판 간이정신상태검사 (Korean version-Mini Mental State Examination, K-MMSE; Kang, 2006) 상에 연령 및 교육수준별 규준에서 정상 범주에 속하여 인지 기능에 문제가 없고, (4) 조금이라도 스스로의 말에 변화가 있다고 보고한 사람이다. 또한, 노화의 과정에서 나타나는 말 변화가 50대 에서도 관찰된다는 선행 연구(Kim, Kim, Park, \& Choi, 2010; Lee $\& \mathrm{Kim}, 2006)$ 에 따라 연령 기준을 55 세 이상으로 선정하였다. 전체 대상자의 평균 연령은 73.19 ( \pm 8.54 )세, 연령 범위는 55세부터 100 세이었다. 평균 K-MMSE 점수는 26.46 ( \pm 2.76$)$ 점이었다. 교육년수 측면에서는 3 년 이하의 교육년수에 해당하는 대상자가 9 명, 4 년 이 상 6년 이하는 14 명, 7년 이상 9년 이하는 17 명, 10 년 이상은 36 명이 었다. 대상자에 대한 기술통계 결과는 Table 1에 제시하였다.

\section{연구절차}

자료수집은 신촌세브란스병원 연구심의위원회(Institutional Review Board, IRB) (IRB No. 4-2017-1232)에서 승인을 받은 후, 총 3개월간(2018년 3-5월) 이루어졌으며, 각 대상자들에게 조사 목적 및 방법에 대해 구두로 설명하고, 서면 동의를 받은 후 진행하였다.

본 연구의 자료는 기본정보 수집, 말 관련 기능 검사, 말 자가인식 조사의 세 단계를 거쳐 수집하였다. 첫 단계는 기본정보수집 단계 
Table 1. Demographic information of participants

\begin{tabular}{lc}
\hline Variables & No. \\
\hline Age $(y r)($ mean $\pm S D)$ & $73.19( \pm 8.54)$ \\
Sex & 23 \\
Male & 53 \\
Female & \\
Education (yr) & 9 \\
$0-3$ & 14 \\
$4-6$ & 17 \\
$7-9$ & 36 \\
$>10$ & $26.46( \pm 2.76)$ \\
K-MMSE $($ mean $\pm S D)$ &
\end{tabular}

$\mathrm{SD}=$ Standard Deviation; $\mathrm{yr}=$ year; K-MMSE = Korean version of Mini-Mental State Examination (perfect score: 30) (Kang, 2006).

로서 대상자의 ‘나이,' '교육년수, '약물을 처방 받은 만성질환의 종 류를 수집하였다. 두 번째 단계는 전반적 인지기능 선별 단계로서 말에 악영향을 줄 수 있는 인지 기능저하를 평가하기 위하여 한국 형 간이정신상태 검사(Korean version-Mini Mental State Examination, K-MMSE; Kang, 2006)를 시행하였다. 세 번째 단계에서는 말 자가인식 조사를 진행하였으며, 제공한 질문은 두 가지이었다. 첫째, 대상자 본인이 말이 변화 되었는지를 인식하고 있는지 여부 를 조사하기 위하여 " 1 년 전에 비하여 말을 하는데 차이가 어떻게 있나요?”라고 질의하였다. 이 문항을 선정한 이유는 예전과 현재를 비교하여 말 수행력이 변화되었는지를 확인하고자 함이었다. 시간 적 참조(즉, ' 1 년 전')를 설정하기 위하여 삶의 질에 대한 여러 자가 보고 연구들을 참조하였으며, 특정한 시간적 범위 동안 대상자들 이 경험한 문제나 호소사항에 대해 '지난 7일(1주) 동안'(Aaronson et al., 1993; DeWalt et al., 2007), 지난 2주 동안'(Min et al., 2000), 지난 4주 동안/한달간'(Brazier et al., 1992; Hays, Kallich, Mapes, Coons, \& Carter., 1994; McHorney et al., 2000; Rector, Kubo \& Cohn, 1993; Shen, Kotsanos, Huster, Mathias, Andrejasich, \& Patrick., 1999) '지난 3개월 동안'(Hellström \& Hallberg, 2001; Shen et al., 1999) 등으로 다양하게 활용되었는데, 본 연구의 대상자가 정상 노년층인 동시에 짧은 기간 내에 변동이 가능한 사회정서적 변인이 아닌 '말'이라는 기능적 측면의 변인임을 감안하여 이들 중 가장 넓 은 범위인 '1년 동안’을 택하였다. 본 문항에 응답 시, 대상자가 말 기 능이 아닌 다른 주제에 대하여 응답하거나, 변화가 없다고 대답하 면, “발음은 어떠세요?”, “목소리는 괜찮으세요?”와 같이 말의 세 분화된 하위 기능에 대하여 추가적인 질문을 제공함으로써, '말'문 제에만 국한하여 응답을 하도록 유도하였다. 둘째, 말 변화로 인하 여 경험한 사회적 활동제한과 참여제약을 확인하고, 이를 통해 말 변화로 인한 삶의 질을 조사하기 위하여 "말 때문에 일상생활에서
불편한 게 있으신가요?”라는 질문을 제공하였다. 만일 대상자가 말 의 차이를 지각한다고 하면, 어떤 문제를 느끼는지 구체적으로 설 명하도록 다시 질문하였다. 대상자의 모든 응답은 추후 전사를 위 하여 녹음기(Sony PCM-10, Sony ICD-UX560F)를 사용하여 녹음 하였다.

\section{자료 분석}

질적 분석은 질적 분석 도구인 Nvivo 12 프로그램(https://www. qsrinternational.com/nvivo/trial)을 사용하였다. Nvivo 12 프로그 램은 프로그램 상에서 발화 전사가 가능하며, 그 자료를 코딩하여 분석한 후, 결과를 시각화하여 도표 혹은 그림으로 산출하는 기능 을 가진 정성적 분석 프로그램이다.

분석은 다음의 절차로 이루어졌다. 첫째, 주제 분석을 위하여 전 사된 응답을 수평적으로 늘어놓았다. 대상자의 응답을 여러 번 읽 어 발화의 의미를 파악하였고, 대상자의 보고가 '주제 발화, 즉 주 제와 관련 있는 발화에 해당하는지를 판단하여 선별하였다. 둘째, 주제 발화에서 확인되는 중심 개념을 바탕으로 제 1 저자가 개방코 딩을 실시하였다. 셋째, 코딩을 완료한 후 질적 연구의 신뢰성 기준 (trustworthiness criteria) 중 신빙성(credibility)을 충족하여 신뢰 로운 연구결과를 산출하기 위하여 2급 언어재활사 자격증을 취득 하고 대학원에서 언어병리학을 전공하는 3 명의 석사과정생으로 구성된 동료지지집단(peer support group)(Guest et al., 2011; Padgett, 2001)에게 코드의 타당성 여부에 대한 의견을 구하였다. 이를 위해 동료지지집단에게 주제 발화와 코드명을 제공하고 각자 자료 를 분석해줄 것을 요청하였다. 제 1 저자를 포함한 4 인의 분석 결과 에서 한 주제 발화를 3 인 이상이 동일하게 코딩을 하면, 그 코드는 신빙성이 있다고 간주되었다. 넷째, 코드를 바탕으로 상위 주제와 하위 주제를 도출하였으며, 이 주제에 대한 타당성 여부는 두 저자 들(Kim, S. \& Kim, H.)이 논의하여 최종적으로 결정하였다. 또한 각 주제의 빈도를 산출하고, 해당하는 발화의 내용을 확인하여 노 년층의 말 자가인식 보고에 내재하는 주제를 확정하였다. 확정된 하위 주제는 NVivo 12 프로그램을 활용하여 보고에서 출현된 빈 도를 바탕으로 단어 구름(word cloud)을 생성하여 시각화하였다.

\section{연구결과}

수집된 자료를 질적 분석한 결과, 주제 발화의 개수는 총 139 개 였으며, 총 4 개의 상위 주제, 총 16 개의 하위 주제가 도출되었다. 첫 번째 상위 주제는 '말 변화의 특색'으로서, 6 개의 하위 주제는 '조 음, '발성', ‘유창성', ‘운율, '말 명료도', ‘호흡’이었다. 두 번째는 '말 
Table 2. Hierarchy of major themes and subthemes

\begin{tabular}{|c|c|}
\hline $\begin{array}{l}\text { Major themes (number of thematic } \\
\text { discourses) }\end{array}$ & $\begin{array}{c}\text { Subthemes (number of thematic } \\
\text { discourses) }\end{array}$ \\
\hline \multirow[t]{6}{*}{ Characteristics of changes in speech (75) } & Articulation (34) \\
\hline & Phonation (18) \\
\hline & Fluency (12) \\
\hline & Prosody (5) \\
\hline & Speech intelligibility (4) \\
\hline & Respiration (2) \\
\hline \multirow[t]{4}{*}{ Causes of changes in speech (46) } & Overall ageing (20) \\
\hline & Dental problems (22) \\
\hline & Diseases (3) \\
\hline & Hearing problems (1) \\
\hline \multirow{3}{*}{$\begin{array}{l}\text { Activity limitations and participation re- } \\
\text { strictions due to changes in speech (9) }\end{array}$} & Singing (6) \\
\hline & Conversation (2) \\
\hline & Vocational activity (1) \\
\hline \multirow[t]{3}{*}{ Solutions to changes in speech (9) } & Verbal training (5) \\
\hline & Nonverbal training (2) \\
\hline & Treatment for diseases (2) \\
\hline
\end{tabular}

변화의 원인'으로서, 4 개의 하위 주제는'전반적 노화', '치아 문제,' '질병' '청력 저하'가 확인되었다. 세 번째 상위 주제는 '말 변화로 인 한 활동제한 및 참여제약' 이며, 이에 따른 3개의 하위 주제는노래', '대화', '직업 활동'이었다. 네 번째는 '말 변화의 해결 방안'으로서 '구어 훈련, '비구어 훈련' '질병 치료' 라는 3 개의 하위 주제가 도출 되었다. 주제의 위계는 Table 2에 제시하였다.

\section{말 변화의 특색}

노년층은 ‘말 변화의 특색’에 대하여 “말이 좀 다르죠, 잘 안돼." 라고 보고하며, 여러 측면에 걸쳐 다양한 응답을 하였다. 말 운동 집 행 과정의 하위 기능 다섯 가지 중에서 '조음, '발성', '운율', ‘호흡'의 네 가지가 하위 주제로 도출되었다. 또 ‘유창성'과 ‘말 명료도'의 문 제에 대하여도 보고하였다. 말 변화 특색에 대해 보고된 빈도에 따 라 생성된 단어 구름을 Figure 1에 제안하였으며, 6 개의 하위 주제 에 대한 내용이 다음에 정리되었다.

\section{조음}

지역사회 거주 노인은 말 자가인식 보고에서 '조음' 문제를 가장 많이 언급하였다. 노년층은 다양한 표현을 사용하여 자신의 왜곡 된 말소리를 묘사하였는데, '말이 샌다', '힘이 없다', '분명하지 않 다, ‘흐릿하다', ‘무겁다', ‘어둔하다', '말이 끌린다’, ‘또랑또랑하지 않 다, '딱딱 떨어지지가 않는다' 등이 있었다. 또한 왜곡이 아니라 대 치, 생략의 문제가 있다고도 보고하였다.

첫 번째 발화(a)에서는 '탄다'를'간다'로 대치한 예시를 통해, 단

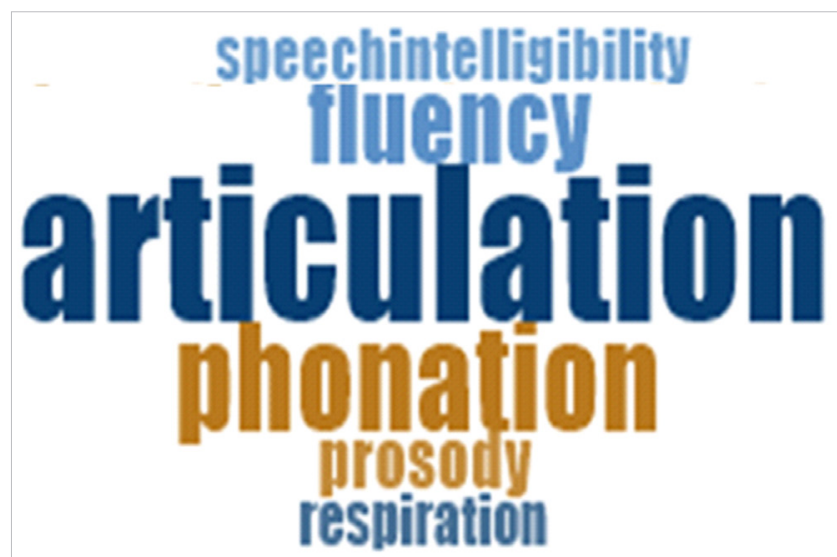

Figure 1. A word cloud of subthemes in "characteristics of changes in speech."

지 말소리가 덜 분명한 정도가 아니라 아예 다른 소리로 바뀌어 버 리는 오류에 대하여 설명하였다. 두 번째 발화(b)는 '잘라진다'라는 표현을 사용하며 '고구마'가 '고마'로 산출된 생략 오류에 대하여 설명하였다.

(a) “발음이 제대로 안돼요. 말하자면 '탄다' 그랬을 때 '탄다’ 라 는 걸 부지런히 해, 저기 뭐야 $\cdots$ 똑바로 해야 되는데 고게 안 되고 발음이 세게 뭐 '간다' 라든지 무슨 뭐 요렇게 그걸 본인 이느껴요. 가끔씩 가다가"

(b) “다른 말로 나오는 게 아니라 잘라지는 거지. 고구... '고구마' 그래야 하는데 '고마' 이렇게 나올 때도 있단 말이야 쉽게 말 해서. 빨리 안 나오고”

\section{발성}

두 번째로 많이 언급된 말 변화 특색은 발성 문제이었다. 주요하 게 보고된 변화는 발성된 음성의 음도나 음량, 음질 측면에서의 문 제였다. 그 중에서도 가장 많이 보고된 변화는 음도 문제로, 고음 산출의 어려움을 호소하였다(a). 또한 (b) 발화의 예에서 한 여성 대 상자는 목소리만으로는 대화 상대방이 자신이 여성이라는 것을 인 지하지 못한다고 토로하였다. 청자는 대화 상대방의 음도가 낮아 성별을 올바르게 판단하지 못하였고, 화자 또한 자신의 목소리에 대한 불만이 높았다. 음질의 문제(c) 또한 보고되었는데, '목이 갈라 져서 고운 소리가 나오지 않는다'고 말하였다. 음질 문제를 보고한 사람들은 대부분 위의 경우처럼 과거에 비하여 음질이 저하되긴 하였지만, 이로 인한 큰 불편함은 느끼지 못한다고 보고하였다.

(a) "목이 한번 아프고 목이 완전히 가라앉아가지고 고음이 안 나 와요."

(b) "아유 목소리는 얼마나 바뀌는지 동사무소에서 전화오면요, 할아버지라고 그래. 그래가지고 내가 스마트폰으로 녹음해가 
지고 들어보면 어유 징그러운 거에요. 그렇게 변했어 목이."

(c) “불편하지는 않은데 내 스스로 목이 그냥갈라지는 느낌. 곱지 를 못하고. 그런게 있어요.”

한편 심한 발성문제를 가지고 있는 경우도 있었는데, 발성 자체 의 어려움을 호소하였다(d).

(d) "제일 힘드는 게 주일날 교회 가서 찬송가가 처음에는 안 나 와. 목소리가 아예 안 나오고 있다가 인제 예배가 끝나갈 때쯤 그때서야 인제 목소리가 나와."

\section{유창성}

세 번째로 많이 언급된 문제는 유창성 문제로, 노년층은 말을 더 듬거나 말이 자연스럽게 나오지 않는다고 보고하였다. 대부분의 경 우 반복을 하게 된다고 하거나(a), 일부 대상자는 더 심하게 발화가 진행되다가 멈추는 현상, 즉 막힘 또한 경험한다고 설명하였다(b). 같은 반복을 보이더라도 두 번째 보고의 대상자는 첫 번째 대상자 보다 더 심한 형태의 비유창성을 보였다. 대상자 (a)는 단어 전체 반 복으로 정상 비유창성에 해당하지만, 대상자 (b)는 단어 내 반복으 로 비정상 비유창성에 해당하기 때문이다(Manning \& DiLollo, 2017). 한편, 세 번째 대상자는 반복뿐만 아니라 더 진전된 유창성 문제인 막힘도 경험하고 있었다. 이를 통해 노년층이 겪는 유창성 문제의 중증도가 다양하다는 점을 확인할 수 있었다.

(a) '발음 그런 건 좀 더듬지. 예를 들어서 '야 이거 좀 가져가' 그 래야 되는데, '야 이거이거 가져가' 이렇게 되지. 말도 더듬는 거 같아. 예를 들어서 '요요요기' 그러면 이렇게 더듬어."

(b) "예 좀 더듬는 거 같다고. 말이 조금 그칠 때가, 말이 나오고 서 이 말을 한다 하는데 딱 그칠 때가 많아요."

\section{운율}

운율 측면에서 노인들은 말 속도, 고저, 강약, 장단의 문제를 보고 하였다. 먼저 말 속도에 대해서는 더 빨라졌다는 경우(a)와 더 느려 졌다는 경우(b)가 모두 있었다.

(a) "우리 애들 말이, 빠르대요."

(b) "그런데 혀가잘 안 꼬부라지니까 좀 늦혀지고..."

한편 대상자(c), (d)는 말의 고저, 강약, 장단을 조절하는 능력이 저하되어 단조롭게 들린다는 특색을 보고하였다.

(c) "책을 읽을 때 그 강약 같은 거, 강하게 할 거 약하게 할 거 그 런 거를 잘 못해요. 이제 고저 장단을 잘 못한다는 애기지."

(d) "그래서 말을 할 때 조금 강조할 때가 있어요. 그래서 좀 딱딱
한 느낌을 내가 받을 때가 있어요. 남들은 모르는데 나만.”

\section{말 명료도}

말 명료도, 즉 타인이 자신의 말을 이해하는 정도와 관련하여 노 년층은 변화를 지각하고 있었다. 노인들은 대화 상대방이 자신의 말을 이해하지 못한 경험에 대해 서술하였다(a). 또한 대상자 (b)는 아직까지 의사소통 실패를 경험한 적은 없고 발음 문제가 있다고 생각하지는 않지만, 자신의 말이 명료한지에 대해서는 확신할 수 없다면서 우려하였다.

(a) "저는 잘 모르겠는데 상대방이 제가 하는 말을 잘 못 알아듣 더라구요."

(b) "일년 전에 비해서 애기하는데 뭐 제가 들었을 때 발음이 정 확하게 다른 사람이 들리는지 싶은 생각이 좀 들어요. 아니 다른 사람이 들었을 때, 나는 그대로 하는데 다른 사람이 제3 자가 들었을 때 정확하게 바로 들리는지 그거는 잘 모르겠다 구요.”

\section{호흡}

말의 변화에 대하여 질문하였을 때, 노년층은 '호흡이 짧아졌다' 는 응답을 하였다. 대상자 (a), (b)는 숨이 차서 말하기가 어렵다고 보고하였다.

(a) “예전에는 호흡이 좀 길었는데 호흡이 좀 많이 짧아졌어요.”

(b) "이제 숨도 좀차가지고 말도 좀 더듬는 거 같아."

\section{말 변화의 원인}

노년층이 보고한 '말 변화에 대한 원인'은 "아무래도 나이가 있다 보니까.”라는 발화로 종합될 수 있었다. 다섯 가지 하위 주제가 도출 되었는데 '일반적 노화’에 해당하는 경우가 가장 많았고, '치아 문 제'와 ‘질병', ‘청력 저하'가 그 뒤를 이었다. 하위 주제의 빈도에 따라 생성된 단어 구름은 Figure 2와 같다.

\section{일반적 노화}

노년층은 나이에 대하여 언급하며, 말 변화의 원인으로 일반적 노화를 언급하였다. 일부는 대상자 (a)와같이 노화로 인한 말 산출 기능의 악화가 진행형이라고 보고하며, 해가 갈수록 조금씩 나빠진 다고 하였다. 그러나 이와 반대로, 대상자 (b)와 같이 특정 나이에 접어들면서 말에 변화가 생겼다고 하는 경우도 있었다.

(a) "저기요 우리 저 조금씩 나빠져요. 나이를 먹으니까 느낌이 조 금씩 나빠지는 거 같아. 제가 느끼기에는 해마다 조금씩 달라 지는 거 같아.” 


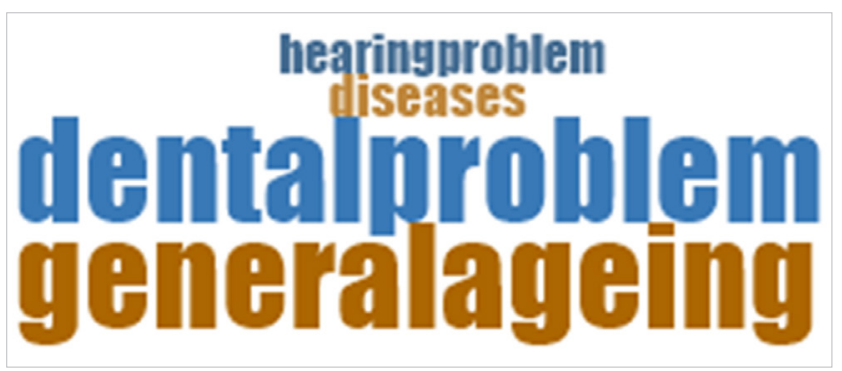

Figure 2. A word cloud of subthemes in "causes of changes in speech."

(b) "나이가. 왜냐면 그전만 해도 내가 75 , 저 일년 전만 해도 내가 괜찮았었는데 $\cdots . "$

\section{치아 문제}

두 번째로 많이 보고된 하위 주제는 치아 문제로, 발음 문제와 연 관되는 경우가 대부분이었다. 발화 (a), (b), (c)에서와 같이 특히 틀 니로 인하여 발음이 정확하지 않고, 입 천장의 이물감으로 말하기 가 불편하다는 경우도 있었다.

(a) “발음이 조금 흐려진다 그럴까, 발음이 흐려지는 느낌. 아 그 게 아마 치아 영향도 있을 거 같아요. 치아에. 바람이 빠지는 듯한 느낌."

(b) "위아래를 틀니를 하니까 어떤 때는 약간 새는 기분으로 발 음이 정확하지 않은 때가 있어요."

(c) "이 천장이 위에 뭐 묻은 거 같아. 이게 틀니 하기 전에는 그런 걸 모르는데 틀니하고 오니까 이 말에서 말이 잘 안 보내지는 거지."

\section{질병}

질병이라는 하위 주제에는 이질적인 주제 발화들이 병합되었다. 인두염(a), 파상풍(b), 당뇨병(c)이 언급되었으며, 특별히 당뇨병의 경우에는 병의 증상 중 하나인 구강건조증이 말에 영향을 준다고 보고하였다.

(a) "그건 인두염을 좀 않았었는데, 인두염 그때부터 목이 좀 안 좋아."

(b) “그렇게 불편함은 없는데 조금 파상풍이 와가지고 … (중략) 처음에는 말을 못했어요. 말을 못하다가 매일 침 맞으러 가고, 매일 병원에 가가지고 입도 조금 돌아오고. 입이 비뚤어졌었 거든. 근데 입이 좀 돌아오고 이제 바로 되기는 됐는데, 말을 약간 더듬어."

(c) "당뇨가 있으니까 말을 많이 하게 되면 입이 마르잖아요."

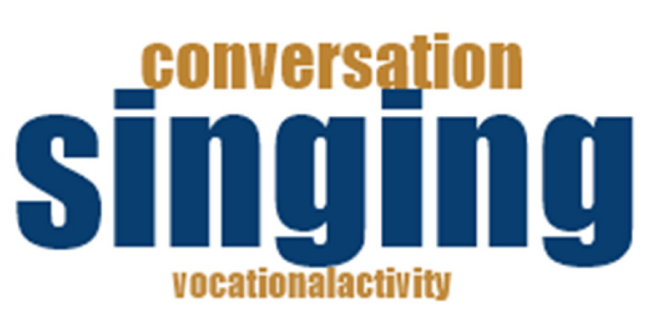

Figure 3. A word cloud of subthemes in "activity limitations and participation restrictions due to changes in speech.”

청력 저하

말 변화의 원인으로 청력 저하를 보고한 경우도 있었다. 대상자 (a)는 청력이 저하되어 대화 상대방의 말소리를 잘 듣지 못해 말이 유창하지 않아진 것 같다고 응답하였다.

(a) "조금 덜 들리다 보니까 말이 조금 더듬더듬 하는 거 같아."

\section{말 변화로 인한 활동제약 및 참여제한}

'말 변화로 인한 활동제약 및 참여제한' 측면에서, 노년층은 말 변화로 인하여 '노래', ‘대화', '직업 활동'이라는 세 가지 하위 주제 를 “이제 못 해.”라고 보고하였다. 생성된 단어 구름은 Figure 3 과 같다.

노래

활동과 참여 측면에서, 가장 많은 비율을 차지한 항목은 노래이 다. 노년층은 발성, 혹은 발음의 문제로 노래를 못하게 되었다고 밝 혔다. 합창단, 노래 대회 등 사회적인 영역에서 제한을 느낀다고 하 는 경우(a)도 있었던 반면, 개인적인 취미생활이나 종교생활에 지 장이 있다고 하는 경우(b)도 있었다. 대상자 (c)는 노래를 부르지 못 해서 불편하다는 부정적인 정서를 내비치기도 하였다.

(a) "아니 대회 나가가지고 연습하는데 목이 안 좋아서 안 해 이제."

(b) "그리고 노래도요 조금 목이 조금 텁텁해가지고 노래도 조금 안 나와요. 나는 노래를 좋아해서 항상 작년까지도 그랬어요. 작년까지도 녹음기를 틀어놓고 앉아서 나 혼자서 테레비 보 면서 한 시간도 노래를 불렀어요."

(c) "아니 노래할 때 노래를 못하니까 불편하지."

대화

노인은 말의 일차적인 목적인 의사소통에서도 제한을 느끼며 대 화 상황에서 어려움이 있다고 설명하였다. 심한 경우, 말의 변화로 인하여 대상자 (a)와 같이 대화 상황을 회피하기도 한다고 밝혔다. 
(a) “그냥 말하기도 그렇고 $\cdots$ 남한테 말하기도 그렇고 그냥 이렇 게 좀피하고."

\section{직업 활동}

말의 변화는 노년층의 직업 활동에도 영향을 미친다고 보고되었 다. 대상자 (a)는 치아 문제로 말 기능이 악화되어 강사직을 내려놓 게 되었음을 털어놓았다.

(a) "발음이 어떨 때는 정확하게 어떤 때는 못할 때는 안 나가니 까 치아 때문에. 3-4년 됐어요. 그전에는 나가서 강사도 하고 강의도 하고 그랬어요. 이거 치아 튼튼 내 치아로 했을 때는 강의도 하고 그랬는데."

\section{말 변화의 해결 방안}

노년층은 말 변화에 따라 스스로 겪고 있다고 생각하는 사회적 활동과 참여에서의 어려움에 대처하기 위하여 다양한 '해결 방안' 을 모색하고 있었으며, “이걸 해야겠구나."라고 깨달은 경험에 대하 여 보고하였다. 이는 ‘구어 훈련', '비구어 훈련', '질병 치료’라는 세 가지 하위 주제로 범주화 되었으며 그 빈도에 따른 단어 구름은 Figure 4 와 같다.

\section{구어 훈련}

구어 훈련으로 보고된 해결 방안으로는 말할 때 정확하게 하고 자 의식적으로 신경을 써서 말하는 것과 읽기 연습이 있었다. 의식 적으로 말을 한다고 응답한 경우는 대부분 발음에 문제가 있다고 스스로 인식하고 있는 경우였다. 발화 (a), (b)와 같이 노년층은 불 분명한 발음을 교정하기 위하여 의식적으로 조음 운동을 수행한다 고보고하였다.

(a) "말하는 데는 틀니가 되다 보니까 발음이 잘 안되죠. 발음이 좀 불편한 거 같고, 될 수 있으면 정확하게 발음하려고 애쓰는 데 그게 잘 안돼서..."

(b) "목이 컬컬해졌고 내가 느낌은 발음이 분명하지 못 한 거 같고. 그래서 말을 할 때 조금 강조할 때가 있어요."

\section{verbaltitratining}

Figure 4. A word cloud of subthemes in "solutions to changes in speech."
한편, 별도로 말 훈련을 한다고 보고한 경우(c)도 있었다. 충분한 연습을 통해 말을 많이 함으로써 말 운동 기능을 강화하여 발음 문 제를 회복하려고 한다고 제시하였다.

(c) “책은 많이 읽으면 글자를 많이 읽을 수 있을 거 같은데 $\cdots$. (중 략) 많이 보면 잘 읽을 수 있을 것 같은데 그런 시간이 많이 가 지려고 노력하죠."

\section{비구어 훈련}

비구어 훈련으로 보고된 해결 방안은 구강 운동과 발성 훈련이 다. 조음 문제를 보고한 대상자 (a)는 구강 운동에 대하여 소개하였 으며, 발성 문제를 가지고 있는 대상자 (b)는 발성 음량 증진 훈련에 대하여 언급하였다.

(a) "왜 이렇게 혀가 맘대로 안 돌아가나, 이게 원활하게 안되기 때문에 혼자 생각을 했어요.'이 혀 운동을 해야되겠구나' (중 략) 그래서 양치할 때 가글을 많이 했어요.”

(b) "소리가 이렇게 좀 저 목소리까지 좀 변했어요. (중략) '산에 가서 악을 한번 써볼까'그런 생각 해요.”

\section{질병 치료}

말 변화의 원인이 특정 질병으로 인한 경우, 대상자들은 원인 질 환을 치료하여 말 문제를 해결하였다. 보고에서 언급된 치료는 약 물치료(a)와 침치료(b)이다.

(a) "약을 먹고 치료를 하고 노력을 많이 했더니 발음은 이제 정 확해져서 괜찮아요."

(b) “그렇게 불편함은 없는데 조금 파상풍이 와가지고... (중략) 처음에는 말을 못했어요. 말을 못하다가 매일 침 맞으러 가고, 매일 병원에 가가지고 입도 조금 돌아오고. 입이 비뚤어졌었 거든. 근데 입이 좀 돌아오고 이제 바로 되기는 됐는데, 말을 약간 더듬어."

\section{논의 및 결론}

자가보고는 대상자가 자신의 문제에 대하여 가지고 있는 인식과 그로 인해 달라진 삶의 질을 측정할 수 있는 설문 평가이다. 정상 노 인은 노화로 인하여 여러 방면에서 말의 변화를 겪을 수 있으며 (Hunter et al., 2012), 이는 노년층의 활동참여를 제한하여 삶의 질 에 영향을 줄수 있다(Ryu et al., 2015). 본 연구는 주제 분석을 통하 여 지역사회 거주 노인의 말 자가인식 보고에서 나타나는 말 변화 의 특색과 원인, 활동참여의 변화, 해결 방안에 대한 상위 주제와 하위 주제를 밝혔다. 본 연구에서 밝혀진 주요 결과와 그에 따른 논 
의점은 다음과 같다.

본 연구결과에서 도출된 첫 번째 상위 주제는 ‘말 변화의 특색’이 다. 노년층은 말의 다섯 가지 하부 기능 중 '호흡, '발성', '조음' '운 율'이라는 네 가지를 보고하였다. 노인들이 스스로 기능 저하를 인 식하고 있다고 보고한 이 특색들은 대부분 선행연구에서 노화의 영향으로 나타날 수 있는 말 문제들이다(Bóna, 2014; D’Alessandro \& Fougeron, 2018; Eichhorn et al., 2017; Gorham-Rowan \& LauresGore, 2006; Goy et al., 2013; Huber, 2008; Huber \& Spruill, 2008; Xue \& Hao, 2003; Marino \& Johns III, 2014). 단, 느린 말 속도를 제 외하고는 운율과 정상 노화의 상관관계는 아직 명확하게 밝혀지지 않았다.

노년층은 '유창성'의 저하로 인하여 말 진행이 방해된다는 점에 대해서도 보고하였다. 선행 연구에 따르면, 노화에 따라 비유창성 은 증가하며(Leeper \& Culatta, 1995), 특히 80대 이후에는 유창성 이 더 심하게 저하된다(Andrade \& Martins, 2010). 이에 본 연구의 결과 또한 선행연구와 맥락을 같이 한다.

더불어 노인들의 보고에서 말 기능의 전반적 수준을 파악할 수 있는 ‘말 명료도’라는 하위 주제를 확인할 수 있었다. 이는 노년층 이 말 산출의 본질적인 목적은 타인과 의사소통하기 위한 것이므 로, 말을 스스로 평가할 때 대화상황에서 자신의 말이 얼마나 기능 적으로 사용되는지를 고려한다는 점을 시사한다. 한편 말 명료도 는 객관적 말 평가에서 장애를 판단할 때 가장 빈번하게 활용되는 항목이다(Blaney \& Hewlett, 2007; Yorkston, Dowden, \& Beukel$\operatorname{man}, 1992)$. 노년층이 자신의 말의 변화에 대하여 스스로 평가할 때에도 이러한 기준을 바탕으로 한다는 것은 자가인식을 보고할 때 비교적 타당한 기준을 가지고 있었음을 시사한다.

두 번째로 도출된 상위 주제인 '말 변화의 원인'에 대하여, 노년층 은 '일반적 노화' 혹은 노화와 관련이 있는 '치아 문제', '청력 저하', '질병'을 원인으로 보고하였다. 즉, 지역사회 거주 노년층은 나이가 직접적 혹은 간접적으로 말에 영향을 준다고 언급하였으며, 신경학 적 질환의 가능성에 대하여는 고려하지 않았다. 더불어 본 연구에 서는 조음 문제의 원인으로 치아 문제를 언급하는 대상자가 다수 있었다. 선행 연구에 따르면, 틀니 착용과 객관적 조음 평가 결과 사 이의 관계에 대하여는 상반된 연구결과가 나타나지만(Knipfer et al., 2012; Stelzle et al., 2017; Wada, Hideshima, Inukai, Katsuki, Matsuura, \& Wakabayashi., 2018), 틀니 착용과 주관적 조음 문제 간에는 정적 상관관계가 있다고 알려져 있다(Hur, Lee, Dong, \& Hong, 2010).

세 번째로 도출된 상위 주제는 '말 변화로 인한 활동제약 및 참여 제한'이다. 노년층은 말 기능의 저하로 '대화' 상황에서 한계를 느끼
고 회피하는 경우도 있다고 보고하였다. 더 나아가 '노래'와 '직업 활동을 더 이상 수행하지 못한다고 하였다. 이를 통해 노년층은 단 순히 의사소통을 위한 말 산출뿐만 아니라, 더 복잡한 기능을 필요 로 하는 사회적 활동에도 참여하기를 원한다는 점을 확인할 수 있 었으며, 이는 선행연구와 일치하는 결과이다(Kim \& Roh, 2018; Lee, Kim, Lim, \& Kim, 2018).

노년층은 다양한 해결책을 사용하여 말 변화에 대처하고 있었 고, 이에 대해서 본 연구의 마지막 상위 주제인 말 변화의 '해결 방 안'을 확인할 수 있었다. 노년층은 ‘구어 훈련’ 및 ‘비구어 훈련’ 방법 을 스스로 모색하여 시도하고 있었다. 또한 원인 질환이 분명한 경 우에는 그 '질병 치료’를 하면 환자가 주관적으로 판단하기에 말 문 제 해결에 효과적이었다는 점을 살펴볼 수 있었다.

본 연구의 의의는 다음과 같다. 본 연구는 지역사회 거주 노인이 자신의 말 기능에 대하여 가지고 있는 인식에 내재된 주제를 도출 하였다. 이를 통하여 노인들이 노화로 인한 말 변화를 스스로 인식 하고 있으며, 자신의 말에서 어떠한 특색을 인지하고, 변화의 원인 이 무엇이라고 생각하는지를 확인할 수 있었다. 더 나아가 노년층 이 말 문제로 인하여 가지고 있는 활동제약과 참여제한이 무엇이 며, 어떤 해결 방안을 사용하여 이를 극복하는지를 밝혔다.

본 연구의 결과로 제시된 주제는 노년층을 대상으로 한 말 언어 치료 목표에 반영될 수 있을 것이다. 노년층은 다양한 말 변화를 인 지하고 있으며, 개인별로 주요하게 호소하는 문제가 다르다. 또한 단순히 대화 상황에서 기능적인 의사소통을 하는 것 이상으로 다 양한 활동과 참여를 수행할 수 있기를 희망하였다. 이에 노인 대상 자의 중재 계획을 구성할 때, 치료를 통해 대상자가 달성하고자 하 는 목표가 무엇인지 확인하는 과정이 반드시 필요하다. 특히 노년 층은 말 특색을 기술하는 데에 있어서 다양한 표현을 사용하며, 말 과 언어, 때로는 인지의 개념을 혼동하는 경우가 많았으므로 이러 한 특징을 면담 과정에서 유념할 필요가 있다.

한편, 노년층은 말의 변화가 병리적 증상, 혹은 징조라고 여기지 않고 단순히 정상 노화의 과정이라고 여긴다는 점이 본 연구를 통 하여 확인되었다. 그러나 실제로 말의 변화는 일부 신경학적 질환 의 주요 증상에 해당하기도 한다(Harel, Cannizzaro, Cohen, Reilly, \& Snyder, 2004; Özsancak, Auzou, \& Hannequin, 2000; Vogel et al., 2012). 예를 들어 본 연구에서 보고된 말 특색 중 발성 저하, 말 속도의 증가, 단조로움 등은 운동저하형(hypokinetic) 마비말장 애의 말 특성 중 일부에 해당한다(Kim, Chung, Lee, \& Kwon, 2014; Duffy, 2005; Skodda \& Schlegel, 2008; Möbes, Joppich, Stiebritz, Dengler, \& Schröder, 2008; Sapir, 2014). 운동저하형 마비말장애의 원인으로는 파킨슨병, 피질기저핵변성 등의 퇴행성 신경학적 질환 
이 있다(Kim \& Kim, 2009). 따라서 말의 변화는 모두 정상 노화의 결과라고 단정지을 수 없다. 그러나 아직 신경학적 질환을 진단받 은 병력이 없는 노인들은 자신의 말 변화에 대하여 인식하고 있음 에도 불구하고, 이것이 건강 이상으로 인한 문제라고는 생각하지 않는다는 점을 본 연구에서 확인할 수 있었다.

더불어 말 변화를 인지하고 이를 해결하고자 해도, 노년층은 전 문가의 도움을 받기보다는 스스로 방법을 모색한다. 이는 노년층 에게 대처방안에 대한 정보가 충분히 제공되지 않았기 때문일 가 능성이 있다. 따라서 노인에게 병리적인 말 기능 저하와 정상적인 말 변화의 차이, 그리고 말 문제가 생겼을 때 대처할 수 있는 방법에 대한 교육이 마련될 필요가 있다.

나아가 본 연구는 임상에서 적용할 수 있을 정도의 5 분 이내의 짧은 인터뷰에서 수집된 자료를 분석하여 주제를 도출하였다. 이 는 실제 임상 평가의 대상자 인터뷰 과정에서 시행할 수 있을 정도 의 길이이다. 이러한 짧은 대화 안에서도 말 문제를 가진 대상자의 자가보고와 그 안에 내재한 주제를 수집할 수 있다는 점을 확인하 였다. 이러한 주관적 자가인식과 객관적 검사 결과를 통한 다층적 인 평가 결과를 통하여 대상자가 가장 필요로 하는 중재 목표가 무 엇인지를 확인할 수 있을 것이다.

본 연구의 제한점과 후속 연구를 위한 제언은 다음과 같다.

첫째, 본 연구의 자료로 활용된 인터뷰 형식은 사회과학분야에 서 질적 연구를 설계하였을 때 도입하는 심층적인 인터뷰와는 대 조적으로 짧고 간략하였다. 또한 대상자와의 만남이 1 회로 제한되 어 대상자에게 자료 해석에 대하여 재확인을 하지 못하였다. 그러 므로 좀 더 긴 시간 동안 충분히 라포(rapport)를 형성한 후 여러 번 에 걸쳐 진행된 인터뷰를 바탕으로 분석된 결과와는 차이가 있을 수 있으므로, 이러한 방식으로 수행될 후속 연구와의 비교 필요성 이 제기된다.

둘째, 본 연구 자료는 노년층의 자가보고로 한정되었으며, 노인이 주로 상호작용하는 가족, 친구 등 주변인들의 의견은 반영하지 못 하였다. 이에 따라 노인이 지각하는 말의 변화가 대화 상대방의 인 식과도 일치하는지를 확인하지 못하였다. 만일 노인 화자는 말 문 제를 인식하지 못함에도 불구하고 청자는 이상을 제기한다면, 대 상자가 적절한 자기감시(self-monitoring)능력을 가질 수 있도록 중 재해야 할 것이다. 반대로 노인 화자는 말 문제를 지각하지만 청자 는 인식하지 못한다면, 화자가 자신의 말에 이상이 있다고 생각하 는 원인을 찾고 의사소통 효능감을 되찾을 수 있도록 면담을 실시 해야 할 것이다.

셋째, 본 연구에서는 자신의 말에 변화가 있다고 보고한 대상자 들의 말 자료에 대해 객관적인 분석을 실시하지 않았다. 이에 대상
자가 말의 변화를 인식한다고 하여도, 실제로 말이 달라졌는지는 확실하지 않다. 따라서 정상 노년층의 말 자가인식 보고가 객관적 말 평가 결과와 비교하여 타당도를 지니고 있는지, 만일 그렇지 않 다면 왜 노년층은 말의 문제가 없는데도 불구하고 말의 변화를 인 식하는지에 대한 후속 연구의 필요성이 제기된다.

요약컨대, 본 연구는 정상 노인들을 대상으로 본인의 말 상태에 대한 자가인식을 확인하고자 한 최초의 질적 연구이다. 자가인식의 내용이 함유하는 바에 따라 본 연구의 결과를 노인들에 대한 의사 소통 삶의 질을 향상시키며 의사소통 문제에 대한 예방교육에 활 용할수 있음을 기대해본다.

\section{REFERENCES}

Aaronson, N. K., Ahmedzai, S., Bergman, B., Bullinger, M., Cull, A., Duez, N. J., ... \& Kaasa, S. (1993). The European organization for research and treatment of cancer QLQC30: a quality-of-life instrument for use in international clinical trials in oncology. Journal of the National Cancer Institute, 85(5), 365-376.

Andrade, C. R. F. D., \& Martins, V. D. O. (2010). Variação da fluência da fala em idosos. Pró-Fono Revista de Atualização Científica, 22(1), 13-18.

Bilodeau-Mercure, M., \& Tremblay, P. (2016). Age differences in sequential speech production: articulatory and physiological factors. Journal of the American Geriatrics Society, 64(11), e177-e182.

Blaney, B., \& Hewlett, N. (2007). Dysarthria and Friedreich's ataxia: what can intelligibility assessment tell us?. International Journal of Language \& Communication Disorders, 42(1), 19-37.

Bóna, J. (2014). Voice onset time and speakers' age: data from Hungarian. Clinical Linguistics \& Phonetics, 28(5), 366-372.

Bothe, A. K., \& Richardson, J. D. (2011). Statistical, practical, clinical, and personal significance: definitions and applications in speech-language pathology. American Journal of Speech-Language Pathology, 20(3), 233-242.

Braun, V., \& Clarke, V. (2006). Using thematic analysis in psychology. Qualitative Research in Psychology, 3(2), 77-101.

Brazier, J. E., Harper, R., Jones, N. M., O’Cathain, A., Thomas, K. J., Usherwood, T., \& Westlake, L. (1992). Validating the SF-36 health survey questionnaire: new outcome measure for primary care. British Medical Journal, 305(6846), 160-164.

Creswell, J. (2013). Qualitative inquiry and research: choosing among five approaches (3rd ed.). Los Angeles: SAGE.

Damico, J. S., \& Simmons-Mackie, N. N. (2003). Qualitative research and 
speech-language pathology: a tutorial for the clinical realm. American Journal of Speech-Language Pathology, 12(2), 131-143.

D’Alessandro, D., \& Fougeron, F. (2018). Réduction de la coarticulation et vieillissement. XXXIIe Journées d'Études sur la Parole, 410-418.

DeWalt, D. A., Rothrock, N., Yount, S., \& Stone, A. A. (2007). Evaluation of item candidates: the PROMIS qualitative item review. Medical care, 45, S12-21.

Dowdle, S. B., Glass, N., Anthony, C. A., \& Hettrich, C. M. (2017). Use of PROMIS for patients undergoing primary total shoulder arthroplasty. Orthopaedic Journal of Sports Medicine, 5(9), 2325967117726044.

Duffy, J. R. (2005). Motor speech disorders: substrates, differential diagnosis, and management (2nd ed.). St. Louis, Mo: Mosby.

Eichhorn, J. T., Kent, R. D., Austin, D., \& Vorperian, H. K. (2017). Effects of aging on vocal fundamental frequency and vowel formants in men and women. Journal of Voice, 32(5), 644.e1-644.e9.

Flynn, K. E., Lin, L., Cyranowski, J. M., Reeve, B. B., Reese, J. B., Jeffery, D. D., ... Bruner, D. W. (2013). Development of the NIH PROMIS ${ }^{\circledR}$ sexual function and satisfaction measures in patients with cancer. The Journal of Sexual Medicine, 10(Suppl 1), 43-52.

Francis, D. O., Daniero, J. J., Hovis, K. L., Sathe, N., Jacobson, B., Penson, D. F., ... McPheeters, M. L. (2017). Voice-related patient-reported outcome measures: a systematic review of instrument development and validation. Journal of Speech, Language, and Hearing Research, 60(1), 62-88.

Gorham-Rowan, M. M., \& Laures-Gore, J. (2006). Acoustic-perceptual correlates of voice quality in elderly men and women. Journal of Communication Disorders, 39(3), 171-184.

Goy, H., Fernandes, D. N., Pichora-Fuller, M. K., \& van Lieshout, P. (2013). Normative voice data for younger and older adults. Journal of Voice, 27(5), $545-555$

Graffiths, P., Ullman, R., \& Harris, R. (2005). Self assessment of health and social care needs by older people: a multi-method systematic review of practices, accuracy, effectiveness and experience. London: National Co-ordinating Centre for NHS Service Delivery and Organisation R\&D (NCCSDO). London: King's College.

Gruber-Baldini, A. L., Velozo, C., Romero, S., \& Shulman, L. M. (2017). Validation of the PROMIS ${ }^{\circledR}$ measures of self-efficacy for managing chronic conditions. Quality of Life Research, 26(7), 1915-1924.

Guest, G., MacQueen, K. M., \& Namey, E. E. (2011). Applied thematic analysis. Los Angeles: Sage.

Harel, B. T., Cannizzaro, M. S., Cohen, H., Reilly, N., \& Snyder, P. J. (2004).
Acoustic characteristics of Parkinsonian speech: a potential biomarker of early disease progression and treatment. Journal of Neurolinguistics, 17(6), 439-453.

Hays, R. D., Kallich, J. D., Mapes, D. L., Coons, S. J., \& Carter, W. B. (1994). Development of the Kidney Disease Quality of Life (KDQOL ${ }^{\mathrm{TM}}$ ) Instrument. Quality of Life Research, 3(5), 329-338.

Hellström, Y., \& Hallberg, I. (2001). Perspectives of elderly people receiving home help on health, care and quality of life. Health \& Social Care in the Community, 9(2), 61-71.

Huber, J. E. (2008). Effects of utterance length and vocal loudness on speech breathing in older adults. Respiratory Physiology \& Neurobiology, 164(3), 323-330

Huber, J. E., \& Spruill, J. (2008). Age-related changes to speech breathing with increased vocal loudness. Journal of Speech, Language, and Hearing Research, 51(3), 651-668.

Hunter, E. J., Kapsner-Smith, M., Pead, P., Engar, M. Z., \& Brown, W. R. (2012). Age and speech production: a 50-Year longitudinal study. Journal of the American Geriatrics Society, 60(6), 1175-1177.

Hur, I. G., Lee, T. Y., Dong, J. K., \& Hong, S. H. (2010). The effects of dental prostheses to the quality of life among the elderly. The Journal of Korean Academy of Prosthodontics, 48(2), 101-110.

Jacobson, B. H., Johnson, A., Grywalski, C., Silbergleit, A., Jacobson, G., Benninger, M. S., \& Newman, C. W. (1997). The voice handicap index (VHI): development and validation. American Journal of Speech-Language Pathology, 6(3), 66-70.

Kang, Y. W. (2006). A Normative Study of the Korean-Mini Mental State Examination (K-MMSE) in the elderly. Korean Journal of Psychology, 25(2), 1-12.

Katzan, I. L., Fan, Y., Uchino, K., \& Griffith, S. D. (2016). The PROMIS physical function scale: a promising scale for use in patients with ischemic stroke. Neurology, 86(19), 1801-1807.

Kim, J. Y., Chung, S. J., Lee, J. H., \& Kwon, M. (2014). Characteristics of dysarthria and cognitive functions in Patients with Parkinson's disease and Parkinson-plus syndrome. Communication Sciences \& Disorders, 19(4), 551-557.

Kim, J., \& Roh, E. (2018). An exploratory study on social participation needs among the elderly: Q-methodological approach. Journal of Korea Gerontological Society, 38(4), 871-889.

Kim, S. W., Kim, H., Park, E., S., Choi., H., S. (2010). Acoustic dharacteristics of normal healthy Koreans with advancing age. Journal of the Korean Soci- 
ety of Speech Sciences, 2(4), 19-28.

Kim, S. W., \& Kim, H. (2009). The senile neurodegenerative dysarthrias. Communication Science \& Disorders, 14(1), 82-95.

Knipfer, C., Bocklet, T., Nöth, E., Schuster, M., Sokol, B., Eitner, S., Nkenke, E., \& Stelzle, F. (2012). Speech intelligibility enhancement through maxillary dental rehabilitation with telescopic prostheses and complete dentures: a prospective study using automatic, computer-based speech analysis. The International Journal of Prosthodontics, 25(1), 24-32.

Lee, B., Kim, D. R., Lim, H., \& Kim, G. (2018). A Convergence study on the happiness and participating desire of economic activity among elderly living alone. Journal of the Korea Convergence Society, 9(8), 109-116.

Lee, H. J., \& Kim, S. J. (2006). Age and sex difference in acoustic parameter of middle age and elderly adult voice, Malsori, 60, 13-28.

Leeper, L., \& Culatta, R. (1995). Speech Fluency: effect of age, gender and context. Folia Phoniatrica et Logopaedica, 47(1), 1-14.

Manning, W. H., \& DiLollo, A. (2017). Clinical decision making in fluency disorders. San Diego: Plural Publishing.

Marino, J. P., \& Johns III, M. M. (2014). The epidemiology of dysphonia in the aging population. Current Opinion in Otolaryngology \& Head and Neck Surgery, 22(6), 455-459.

McHorney, C. A., Bricker, D. E., Kramer, A. E., Rosenbek, J. C., Robbins, J., Chignell, K. A., ... \& Clarke, C. (2000). The SWAL-QOL outcomes tool for oropharyngeal dysphagia in adults: I. conceptual foundation and item development. Dysphagia, 15(3), 115-121.

Min, S. K., Lee, C. I., Kim, K. I., Suh, S. Y., \& Kim, D. K. (2000). Development of Korean Version of WHO Quality of Life Scale Abbreviated Version (WHOQOL-BREF). Journal of Korean Neuropsychiatric Association, 39(3), 571-579.

Möbes, J., Joppich, G., Stiebritz, F., Dengler, R., \& Schröder, C. (2008). Emotional speech in Parkinson's disease. Movement Disorders, 23(6), 824-829.

Nowell, L. S., Norris, J. M., White, D. E., \& Moules, N. J. (2017). Thematic analysis: striving to meet the trustworthiness criteria. International Journal of Qualitative Methods, 16(1), 1609406917733847.

Ocampo, J. M. (2010). Self-rated health: importance of use in elderly adults. Colombia Medica, 41(3), 275-289.

Özsancak, C., Auzou, P., \& Hannequin, D. (2000). Dysarthria and orofacial apraxia in corticobasal degeneration. Movement Disorders, 15(5), 905-910.

Padgett, D. (2001). Qualitative method in social work research: challenges and rewards (T. K. Yoo, Trans.). Thousand Oaks, CA: Sage.

Rector, T. S., Kubo, S. H., \& Cohn, J. N. (1993). Validity of the Minnesota Liv- ing with Heart Failure questionnaire as a measure of therapeutic response to enalapril or placebo. The American Journal of Cardiology, 71(12), 11061107.

Rinkel, R. N., Leeuw, I. M. V. d., van Reij, E. J., Aaronson, N. K., \& Leemans, C. R. (2008). Speech handicap index in patients with oral and pharyngeal cancer: better understanding of patients' complaints. Head \& Neck: 30(7), 868-874.

Ryu, C. H., Han, S., Lee, M. S., Kim, S. Y., Nam, S. Y., Roh, J. L., ... Choi, S. H. (2015). Voice changes in elderly adults: prevalence and the effect of social, behavioral, and health status on voice quality. Journal of the American Geriatrics Society, 63(8), 1608-1614.

Sapir, S. (2014). Multiple factors are involved in the dysarthria associated with Parkinson's disease: a review with implications for clinical practice and research. Journal of Speech, Language, and Hearing Research, 57(4), 1330-1343.

Shen, W., Kotsanos, J., Huster, W., Mathias, S., Andrejasich, C., \& Patrick, D. (1999). Development and validation of the diabetes quality of life clinical trial questionnaire. Medical Care, 37(4), AS45-AS66.

Skodda, S., \& Schlegel, U. (2008), Speech rate and rhythm in Parkinson's disease. Movement Disorders, 23(7), 985-992.

Spiegel, B. M., Hays, R. D., Bolus, R., Melmed, G. Y., Chang, L., Whitman, C., ... Reise, S. (2014). Development of the NIH patient-reported outcomes measurement information system (PROMIS) gastrointestinal symptom scales. The American Journal of Gastroenterology, 109(11), 1804-1814.

Stelzle, F., Riemann, M., Klein, A., Oetter, N., Rohde, M., Maier, A., ... Knipfer, C. (2017). Long-term outcome of apeech intelligibility in maxillary dental rehabilitation with full dentures: a prospective study using automatic speech quantification. International Journal of Prosthodontics, 30(5), 419-425.

Vogel, A. P., Shirbin, C., Churchyard, A. J., \& Stout, J. C. (2012). Speech acoustic markers of early stage and prodromal Huntington's disease: a marker of disease onset?. Neuropsychologia, 50(14), 3273-3278.

Wada, J., Hideshima, M., Inukai, S., Katsuki, A., Matsuura, H., \& Wakabayashi, N. (2018) Influence of oral morphology on speech production in subjects wearing maxillary removable partial dentures with major connectors. Folia Phoniatrica et Logopedica, 70(3-4), 138-148.

Xue, S. A., \& Hao, G. J. (2003). Changes in the human vocal tract due to aging and the acoustic correlates of speech production: a pilot study. Journal of Speech, Language, \& Hearing Research, 46(3), 689-701.

Yim, A. R., Kim, H., Kim, S. R., \& Yoo, H. J. (2013). Review on age-related 


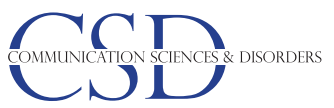

voice changes and quality of life. Journal of Rehabilitation Research, 17(1), 259-276.

Yorkston, K. M., Dowden, P. A., \& Beukelman, D. R. (1992). Intelligibility measurement as a tool in the clinical management of dysarthric speakers. In R. D. Kent (Ed.), Intelligibility in Speech Disorders: Theory, measurement,
지역사회 거주 노인의 말 자가인식 보고에 대한 주제 분석 - 김수민 외

and Management (pp 265-286). Amsterdam, John Benjamin Pub.

Yorkston, K. M., Bourgeois, M. S., \& Baylor, C. R. (2010). Communication and aging. Physical Medicine and Rehabilitation Clinics of North America, 21(2), 309-319. 


\section{국문초록}

\section{지역사회 거주 노인의 말 자가인식 보고에 대한 주제 분석}

김수민 ${ }^{1,2} \cdot$ 김향희 ${ }^{1,3} \cdot$ 남석인 ${ }^{4}$ 김한샘5

${ }^{1}$ 연세대학교 대학원 언어병리학협동과정, ${ }^{2}$ 서울아산병원 신경과, ${ }^{3}$ 연세대학교 의과대학 재활의학교실 및 재활의학연구소, ${ }^{4}$ 연세대학교 사회복지대학원, ${ }^{5}$ 연세대학교 언어정보연구원

배경 및 목적: 자가보고는 자신의 문제에 대한 인식과 그로 인한 삶의 질의 변화를 측정한다. 노화가 진행됨에 따라 말은 변화하며, 활 동참여를 방해한다. 본 연구는 주제 분석 방법을 적용하여 지역사회 거주 노인의 말 자가인식에 대한 보고에서 출현하는 주제들을 조 사하였다. 방법: 서울 시내 총 세 곳의 지역사회 노인복지관에서76명의 대상자를 모집하였다(남:여 $=23: 53$, 평균 연령 $=73.19 \pm 8.54$ 세). 대상자는 “1년 전에 비하여 말을 하는데 어떻게 차이가 있나요?", "말 때문에 일상생활에서 불편한 게 있으신가요?”라는 질문에 대하 여 말의 변화와 활동제한, 참여제약 경험을 보고하였다. 분석에는 NVivo 12 프로그램을 사용하였다. 결과: 첫 번째 상위주제는 말 변화 의 특색으로서 ‘조음' '발성' '유창성', '운율', '말 명료도' ‘호흡’이라는 하위주제가 도출되었다. 두 번째는 말 변화의 원인으로서 ‘일반적 노화', '치아 문제', '질병', ‘청력 저하’라는 하위주제가 확인되었다. 세 번째는 말 변화로 인한 활동제한 및 참여제약으로서 ‘노래', '대화', '직업 활동’이라는 하위주제가 나타났다. 네 번째는 말 변화의 해결 방안으로서 '구어 훈련' '비구어 훈련', '질병 치료' 라는 하위주제가 도출되었다. 논의 및 결론: 노인들은 다양한 측면에서 말의 변화를 경험하며, 그 원인이 노화의 영향이라고 생각한다. 또한 활동참여 문 제를 겪으며, 개별적으로 해결책을 적용하고 있다. 본 연구의 결과가 정상 노인을 대상으로 한 의사소통 문제에 대한 예방교육이나 의사 소통 삶의 질 증진을 위하여 유용하게 활용되리라 기대된다.

핵심어: 노화, 노년층, 말, 자가인식, 주제 분석

이 논문은 2017년 대한민국 교육부와 한국연구재단의 지원을 받아 수행된 연구임(No. NRF-2017S1A5A2A01025920).

본 논문은 제 1 저자의 연세대 석사학위논문을 발췌 및 수정한 것임.

본 논문의 일부 내용은 2018년 ASHA 학술대회(미국 보스턴)에서 발표되었음.

\section{참고문헌}

강연욱(2006). K-MMSE (Korean-Mini Mental State Examination)의 노인 규준 연구. 한국심리학회지:일반, 25(2), 1-12.

김선우, 김향희(2009). 노인 퇴행성 신경질환의 마비말장애 특성. 언어청각장애연구, 14(1), 82-94.

김선우, 김향희, 박은숙, 최홍식(2010). 노령화에 따른 건강한 정상 성인의 음향음성학적 특성 비교. 말소리와음성과학, 2(4), 19-28.

김자영, 정선주, 이재홍, 권미선(2014). 특발성 파킨슨병과 파킨슨플러스 증후군 환자의 마비말장애 및 인지기능 특성 비교. Communication Scienc-

es \& Disorders, 19(4), 551-557.

김정현, 노은영(2018). 노년기 사회참여 욕구에 관한 탐색적 연구. 한국노년학, 38(4): 871-889

민성길, 이창일, 김광일, 서신영, 김동기. (2000). 한국판 세계보건기구 삶의 질 간편형 척도(WHOQOL-BREF)의 개발. 신경정신의학, 39(3), 571-579.

유태균 (역) (2001). 사회복지 질적 연구방법론. D. Padgett의 Qualitative method in social work research: challenges and rewards. 서울: 나남.

이병임, 김두리, 임효남, 김광환(2018). 독거노인의 행복과 경제활동의 참여욕구에 대한 융합 연구. 한국융합학회논문지, 9(8), 109-116.

이효진, 김수진(2006). 장 노년기 성인 음성의 성별과 연령에 따른 음향음성학적 특성 비교. 말소리, 60, 13-28.

임애리, 김향희, 김수련, 유현지(2013). 문헌분석을 통한 노화에 따른 음성의 특징과 삶의 질 변화. 재활복지, 17(1), 259 276.

\section{ORCID}

김수민(제1저자, 언어재활사 http://orcid.org/0000-0003-3201-619X); 김향희(교신저자, 교수 http://orcid.org/0000-0003-4949-2512); 남석인(공동저자, 교수 http://orcid.org/0000-0001-8053-0690); 김한샘(공동저자, 교수 http://orcid.org/0000-0001-7495-9466) 